\title{
What is the Fate of the River Waters of Hudson Bay?
}

\author{
P. St-Laurent ${ }^{\mathrm{a}, 1, *}$, F. Straneo ${ }^{\mathrm{b}}$, J.-F. Dumais ${ }^{\mathrm{a}}$, D.G. Barber ${ }^{\mathrm{c}}$ \\ ${ }^{a}$ Institut des Sciences de la Mer, Université du Québec à Rimouski, 310 Allée des Ursulines, Rimouski, Québec G5L 3A1, Canada \\ ${ }^{b}$ Department of Physical Oceanography, Woods Hole Oceanographic Institution, MS 21, Woods Hole, MA 02543, USA \\ ${ }^{c}$ Centre for Earth Observation Science, University of Manitoba, Wallace Building, 125 Dysart Rd, Winnipeg, Manitoba R3T 2N2, Canada
}

\begin{abstract}
We examine the freshwater balance of Hudson and James bays, two shallow and fresh seas that annually receive $12 \%$ of the panArctic river runoff. The analyses use the results from a 3-D sea ice-ocean coupled model with realistic forcing for tides, rivers, ocean boundaries, precipitation, and winds. The model simulations show that the annual freshwater balance is essentially between the river input and a large outflow toward the Labrador shelf. River waters are seasonally exchanged from the nearshore region to the interior of the basin, and the volumes exchanged are substantial (of the same order of magnitude as the annual river input). This lateral exchange is mostly caused by Ekman transport, and its magnitude and variability are controlled by the curl of the stress at the surface of the basin. The average transit time of the river waters is 3.0 years, meaning that the outflow is a complex mixture of the runoff from the three preceding years.
\end{abstract}

Keywords: freshwater, rivers, sea ice, polar, Arctic, Hudson Bay

PACS: 92.10.Sx, 92.10.Fj, 92.10.ak, 92.10.A-

\section{Introduction}

Seasonal changes in insolation at high latitudes lead to air temperatures above and below the freezing point of water. This causes the seasonal storage of water in snow and ice during winter, which is released as liquid water by the melting of snow and ice in spring and summer. Such seasonal variability can be observed in Hudson + James bays (HJB), a shallow and semienclosed basin located upstream of the Labrador Shelf and Current (Fig. 1). The river discharge in HJB fluctuates by a factor of three over seasons (Déry et al., this issue), with a mean value of $635 \mathrm{~km}^{3} \mathrm{y}^{-1}$, or $12 \%$ of the total pan-Arctic runoff (Lammers et al., 2001). This value represents the annual addition of a $80 \mathrm{~cm}$ layer of freshwater if distributed over the whole area of the basin. Satellite observations show the formation of a complete ice cover around December and its complete disappearance by early summer (Hochheim et al., this issue). The thickness of the ice cover is only known from measurements nearshore and qualitative estimates from satellite images that range between one and two meters during the peak of winter (Markham, 1986; Prinsenberg, 1988). The precipitation $P$ and evaporation $E$ rates over the basin are also difficult to estimate from the limited observations, and the literature provides conflicting estimates: Prinsenberg (1980) suggests a negative $P-E$ rate, while Fig. 2.5 from Gill (1982) suggests a positive rate of $290 \mathrm{~kg} \mathrm{~m}^{-2} \mathrm{y}^{-1}$ at $60^{\circ} \mathrm{N}\left(\approx 220 \mathrm{~km}^{3} \mathrm{y}^{-1}\right.$ for $\left.\mathrm{HJB}\right)$. Nevertheless these values of $P-E$ remain smaller than the annual runoff or ice melt by a factor of two or more (see Straneo

\footnotetext{
${ }^{*}$ Corresponding author

Email address: pierre@ccpo.odu.edu (P. St-Laurent)

${ }^{1}$ Present address: Center for Coastal Physical Oceanography, Old Dominion University, 4111 Monarch Way, Norfolk, VA 23508, USA.
}

and Saucier, 2008a, on the freshwater of HJB, Foxe Basin, and Hudson Strait).

A recent observational study highlights how the outflow from Hudson Strait (the channel linking HJB to the Labrador Sea) is a significant contributor to the freshwater flux over the Labrador Shelf, both by conveying the freshwater from HJB and by recycling part of the Baffin Current (Straneo and Saucier 2008b). The variability and magnitude of this fresh outflow is only weakly related to local wind forcing, and the importance of an upstream control (i.e. from HJB) is suggested by these authors (see also Sutherland et al., this issue). Such upstream-todownstream relationship was examined by Myers et al. (1990) who calculated lagged-correlations between salinities from the Labrador Shelf and interannual river discharge or ice volume from HJB. They obtained a significant inverse correlation between the runoff and the salinity by assuming a point-wise runoff and a travel time of nine months before reaching the shelf. A more sophisticated river water tracking algorithm by Déry et al. (2005) recently illustrated how the salinity minimum recorded at the shelf would be in fact a combination of the runoff from three different years owing to the spatially-distributed runoff inside the large basin.

Although the studies from Myers et al. (1990) and Déry et al. (2005) differ regarding the time required to reach the Labrador Shelf, they both assume freshwater to be advected as in a pipeline: the outflow downstream is solely determined by the freshwater input upstream (scenario 1). This will not be the case if processes within HJB act to spatially redistribute the freshwater and complicate its pathway (scenario 2). For instance, the plume of the Mackenzie River in the Beaufort Sea sometimes stretches $400 \mathrm{~km}$ off the shelf (Macdonald et al., 
1999). Such interactions with the offshore region matters for the climate of the bay, its ecosystem, and its biogeochemical conditions. Riverine freshwater increases the stability of the water column and thus exerts a control on the mixing and formation of the bays' waters. The river waters also impact the primary production, the basic component of the food web, which relies on vertical exchanges with nutrient-rich deep waters (e.g., Kuzyk et al. 2010; Sibert et al., this issue). Finally, the spatial redistribution of the riverine tracers is likely to be different according to the scenario. These tracers include colored dissolved organic matter (CDOM, Granskog et al. 2007), which absorb the light necessary for the primary production, and also mercury, a contaminant found in very high concentrations in marine mammals, and a concern for the health of the northern residents (Hare et al., 2008).

The objective of this study is to determine the kinematics, or fate, of the river waters of HJB. More specifically, we investigate the following aspects: To what extent do the river waters spread to the interior region of the basin? Which processes control the exchanges with the interior? What is the transit time of the river waters? Answering these questions will help us determine the role of the river waters at the regional scale. The next sections describe the methodology of the study and the results obtained for the annual freshwater and volume budgets of the basin, the cross-shore exchanges of freshwater and associated process, and the transit time of the river waters.

\section{Method}

\subsection{The Sea Ice-Ocean Coupled Model and its Forcings}

For this study we make use of a regional 3-D numerical model developed by Saucier et al. (2004a). Our study specifically focuses upon the Hudson and James bays (referred to as HJB) even though the model domain also includes Hudson Strait and Foxe Basin. The ocean module (Backhaus, 1983, 1985) solves the primitive equations with a resolution of $10 \mathrm{~km}$ in the horizontal and $10 \mathrm{~m}$ in the vertical. The internal Rossby radius of deformation is about $10 \mathrm{~km}$ in $\mathrm{HJB}$ so that the model partially resolves the mesoscale eddies (eddy-permitting). The ocean model is coupled to a dynamic and thermodynamic twolayer sea ice model (see Hunke and Dukowicz, 1997; Semtner, 1976) and a single layer snow model. As in Saucier et al. (2004a), the prognostic equations are integrated without having recourse to nudging or restoring conditions.

The simulations are initialized from a composite of historic salinity-temperature profiles (see Saucier et al. 2004a) and conducted under realistic forcing from tides, ocean boundaries, river runoff, and atmosphere. Tides are introduced by prescribing the sea elevation at the open boundaries according to Matsumoto et al. (2000). Temperature and salinity at these boundaries are set according to historic profiles acquired at the mouth of Hudson Strait (Canadian Marine Environmental Data Service) and in Fury \& Hecla Strait (Barber, 1965; Sadler, 1982). Observed daily river runoff is obtained from provincial institutions of Québec, Ontario, Manitoba, and from HYDAT (HYdrometric DATabase, Environment Canada) when available. Note that this runoff dataset includes the effect of dams and diversions around HJB. Three-hourly winds and precipitation are taken from the high-resolution $(15 \mathrm{~km})$, data-assimilating, operational model used for weather forecast in Canada (GEM, Global Environmental Model, Côté et al., 1998).

The simulations are conducted using the same model configuration as in the study of Saucier et al. (2004a) except for several minor enhancements. First, the atmospheric and hydrologic forcing was extended to cover the period of the simulation. Then, the air-ocean drag coefficient was updated according to Zedler et al. (2009, Table A2, right column). The air-ice drag coefficient is $1.2 \times 10^{-3}$ as suggested by Hibler (1979). Finally, the model was modified for the use of salty sea ice (7 psu, e.g. Prinsenberg 1984) instead of pure fresh sea ice. It is found that these modifications have only a small effect on the simulated seasonal cycle, but they are nevertheless included for completeness.

\subsection{Spin-up of the Model}

The model results presented in this study are obtained using the following strategy. The model is first spun-up from rest using repeatedly the forcing for the period August 2003 to August 2004 (we did not consider spinning the model using interannually-varying forcing since only four years of continuous data were available.) The spin-up process ends once we obtain a stable seasonal cycle for the salinity and temperature fields. Trends in these fields rapidly disappear within five years of spin-up, and all transient oscillations have disappeared after 20 years. It is this stable seasonal cycle that is used for all the calculations and figures.

\subsection{Comparison with Observations}

Extensive comparisons between the model and observations are available in the work of Saucier et al. (2004a). We nevertheless present here a comparison with observations recently acquired during the ArcticNet and Merica cruises. We specifically show the salinity field since it largely controls the density of the waters (and thus the pressure field and its gradient) and the local concentration of freshwater. The top panel of Fig. 2 shows the surface salinity in late summer for the model (year 2003) and observations (year 2005, see Lapoussière et al. 2009). Although the years are different, the main features of the salinity field are preserved over years and apparent in both observations and model results, notably the relatively fresh boundary region and the saltier interior region. We also note that the location of the isohalines and their spacing (gradient) are similar in a) and b). The bottom part of Fig. 2 shows a salinity transect along $61^{\circ} \mathrm{N}$ from the Merica cruises (Saucier et al., 2004b) and for the same year as in the simulation. Again the model reproduces the key features of the salinity field, including the wedge of freshwater in the eastern part and the saltier interior. The model is slightly too stratified around $30 \mathrm{~m}$ (a frequent problem with statistical closure schemes, Martin 1985) and slightly underestimates the salinity of the mixed bottom layer (the model gives values around $32.9 \mathrm{psu}$ ). Nevertheless this comparison confirms that the high-resolution forcings lead to a realistic solution, and 
that the model is able to reproduce the main dynamical processes governing the freshwater balance of the basin.

\subsection{Choice of the Reference Salinity}

Following McPhee et al. (2009), we define one cubic meter of seawater as a mixture of salty ocean water (of fixed salinity $\left.S_{0}\right)$ and of freshwater $(S=0 \mathrm{psu})$. The local freshwater concentration, $0 \leq c_{\mathrm{fw}} \leq 1$, is thus defined as:

$$
c_{\mathrm{fw}}=\left\{\begin{array}{cc}
\left(S_{0}-S\right) / S_{0} & \text { if } S \leq S_{0}, \\
0 & \text { if } S>S_{0} .
\end{array}\right.
$$

Note that some authors allow $c_{\mathrm{fw}}$ to be negative when $S>S_{0}$. In our case these two definitions are equivalent since the reference salinity $S_{0}=33 \mathrm{psu}$ corresponds to the salinity of the bottom layer (see Fig. 2c) or similarly to the maximum salinity of the waters entering HJB (32.8 psu according to Prinsenberg, 1984). Also note that the model calculations are independent of the $c_{\mathrm{fw}}$ definition since the model dynamics are written in term of absolute densities. The choice of $S_{0}$ only impacts the freshwater budget that is computed a posteriori from the model salinities and velocities.

Previous studies used similar values for the salinity reference of HJB (32.8 psu for Prinsenberg 1984; 33.1 psu for Granskog et al. 2007). The use of a higher reference salinity, such as $S_{0}=34.8 \mathrm{psu}$, would only scale (roughly double) the freshwater content of the basin and the freshwater fluxes at its mouth. Since both inflowing and outflowing fluxes would be scaled, the higher reference value would represent a larger volume of freshwater transiting through the basin, with no net effect on its budget. The definition of freshwater above is also appropriate for the sea ice, with the exception that water is denser than ice, so that a density ratio is taken into account during the calculations.

\subsection{Treatment of Ice Growth and Ice Melt}

The coupling between the sea ice and ocean models results in fluxes of freshwater and brine at the ice-ocean interface. These fluxes are modeled as diffusive fluxes, meaning that ice growth/melt results in a modification of the salinity of the upper ocean (a salt adjustment) while the volume of the water column is unaltered (an approximation commonly used in ocean models; e.g. in the Regional Ocean Modeling System, ROMS). For a grid cell located in the surface level of the ocean model, the salt adjustement corresponds to (e.g., Mellor and Kantha, 1989, Eq. 20):

$$
\left(S^{\prime}-S\right) \rho_{\text {wat }} \Delta x \Delta y \Delta z=\left(S-S_{\text {ice }}\right) \rho_{\text {ice }} \Gamma \Delta t A \Delta x \Delta y,
$$

where $\Delta x \Delta y \Delta z$ is the volume of the cell considered, $S\left(S^{\prime}\right)$ is its salinity in $\mathrm{g} / \mathrm{kg}$ before (after) the salt adjustment, $\rho_{\text {wat }}$ and $\rho_{\text {ice }}$ are the density of water and ice, $S_{\text {ice }}$ the salinity of ice, $\Gamma$ the rate of ice growth or melt (in $\mathrm{m} \mathrm{s}^{-1}$, positive for growth), and $0 \leq A \leq 1$ the fraction of the cell that is ice-covered. The left hand side of Eq. 2 represents the change in the salt content (in grams) of the cell, and this is equal to the amount of salt that must be rejected by the newly formed ice to go from a salinity $S$ to a salinity $S_{\text {ice }}$ (right hand side of Eq. 2; note that $S>S_{\text {ice }}$ ).
The same equation is used for ice melt $(\Gamma<0)$, and its impact on the freshwater budget is best seen by comparing the freshwater content $\left(\right.$ in $\mathrm{m}^{3}$ ) of the cell before and after the salt adjustment. Using Eqs. 1 and 2, this is:

$$
\Delta x \Delta y \Delta z[\overbrace{\frac{S_{0}-S^{\prime}}{S_{0}}}^{\text {after }}-\overbrace{\frac{S_{0}-S}{S_{0}}}^{\text {before }}]=-\frac{S-S_{\text {ice }}}{S_{0}} \frac{\rho_{\text {ice }}}{\rho_{\text {wat }}} \Gamma \Delta t A \Delta x \Delta y .
$$

Eq. 3 shows that the freshwater involved in the growth (melt) of ice is directly subtracted (added) to the freshwater content of the upper ocean during the salt adjustment. The factor $\rho_{\text {ice }} / \rho_{\text {wat }}$ takes into account the difference of density between ice and water, while the factor $\left(S-S_{\text {ice }}\right) / S_{0}$ is necessary when $S_{\text {ice }} \neq 0$ (here $S_{\text {ice }}=7 \mathrm{psu}$ ).

This adjustment of the surface ocean salinity can result in both the destabilization of the upper water column (during ice growth) or its stabilization (during ice melt). The vertical turbulence closure model takes into account these conditions in its budget of turbulent kinetic energy (see Mellor and Yamada, 1982; Canuto et al., 2001, for a description of the turbulence model). Relatively high levels of turbulent kinetic energy and vertical mixing are produced during sustained periods of ice growth, and the opposite during ice melt.

\subsection{Passive Numerical Tracer}

The study presents results from experiments involving a passive numerical tracer that is injected into the system at the same rate and locations as the river waters (e.g., Jahn et al., 2010). A concentration of one (zero) in a given location corresponds to pure (absence of) river water. With this tracer we aim to track the river waters in the most realistic way possible, so that we must take into account the seasonal transformation of these waters into sea ice. The contribution from the river waters to the local ice growth/melt rate $\left(\Gamma\right.$, in $\left.\mathrm{m} \mathrm{s}^{-1}\right)$ is defined as:

$$
\Gamma \frac{c_{\mathrm{riv}}}{c_{\mathrm{fw}}} .
$$

During the ice growth period $(\Gamma>0), c_{\text {riv }}$ is the concentration of the river tracer in the first (surface) model level, and $c_{\mathrm{fw}}$ is the freshwater concentration in the same level. During the ice melt period $(\Gamma<0), c_{\text {riv }}$ is the thickness of solid river tracer, and $c_{\mathrm{fw}}$ is the ice thickness. Note that $c_{\mathrm{riv}} \leq c_{\mathrm{fw}}$ at all times. The solid river tracer is advected using the ice velocities.

This procedure allows us to track the river tracer during the whole year in a realistic manner. The procedure is not the most appropriate for substances such as mercury (that are rejected when ice forms), but it will be seen later (Fig. 7a) that most of the river water remains liquid during winter (e.g., Macdonald et al., 1995), which minimizes this issue. Another disadvantage of having the river tracer involved in the ice growth/melt cycle is that we must consider both solid and liquid fluxes of river tracer. It will be shown later that the movements of river tracer mostly occur during the ice-free period (Fig. 7b), which also minimizes this issue. 


\section{Results}

\subsection{The Annual Freshwater Budget}

The freshwater budget of a coastal basin describes how the various processes balance each other so that the freshwater content of the basin is maintained on long timescales. Table 1 shows this budget calculated from the annual mean of the simulation starting in August 2003 and ending in August 2004 (see Method). The top part of the table describes a balance between the riverine and atmospheric inputs of freshwater, the effect from ice growth and ice melt, and the net lateral exchange of freshwater at the mouth of the system. The growth and melt of ice over HJB as a whole nearly cancel each other, and the spatial distribution of ice growth and melt within the basin is similar to that of Saucier et al. (2004a, their Figs. 10 and 13). The fact that ice growth and melt mostly offset each other for HJB as a whole is also visible in Fig. 3: during winter the liquid and solid components change at the same rate and the total volume of freshwater (red curve) is constant. Over May to October a small increase in total freshwater is visible and it is most likely related to the seasonal river forcing (Saucier et al. 2004a, their Fig. 2f; Déry et al., this issue).

The fluxes through the four channels bounding HJB in the north (Fig. 1) are shown in the lower part of Table 1. Relatively small amounts of freshwater enter HJB through the west (negative fluxes), so that the bulk of the exchange is a large freshwater flux leaving HJB through the easternmost channel. The magnitude of this freshwater outflow $\left(802 \mathrm{~km}^{3} \mathrm{y}^{-1}\right)$ is consistent with measurements made downstream of HJB (760-880 $\mathrm{km}^{3} \mathrm{y}^{-1}$, or 24-28 mSv, Straneo and Saucier 2008b, Table 2). The volume fluxes describe a similar pattern with inflow in the west and outflow in the east. The net volume flux nearly equates the river inflow since all other sources of volume in the budget (e.g. $P$ and $E$ ) are parameterized as diffusive fluxes, which means that they do not modify the volume of the basin. In all cases the volume contribution from $P-E$ is negligible compared to the changes associated with the volume fluxes at the mouth of the bay.

The annual freshwater budget illustrates that the basin mostly exports freshwater from local sources (rivers and net precipitation), and that the river runoff is the most important contributor to the annual budget. The next sections focuses upon these important river waters and more specifically on their trajectory within the basin.

\subsection{The Fate of the River Waters}

In order to track the river waters numerically we tag them with a passive tracer described in Method. Figure 4a shows the surface concentration of the river tracer once its concentration has reached steady-state. The concentration is shown for the summer period when observations of the surface salinity are available for comparison (see Method for a description of the data). The figure shows that the highest concentrations are found near the shorelines, and that most river plumes are deflected toward the right as expected from the Coriolis force. The tracer field evolves over time by moving in a counter-clockwise sense and leaving through Hudson Strait, which is consistent with the known currents of the basin (Prinsenberg, 1986a). What is less expected is that the river waters seem to be only loosely trapped to the coastlines, leaking toward the interior of the basin at scales of $100 \mathrm{~km}$ rather than $10 \mathrm{~km}$.

As it will be shown later, this seaward transport of the river tracer is driven by genuine physical processes rather than artificial effects such as numerical or subgrid scale diffusion. The existence of such seaward transport is supported by a certain number of observations. Granskog et al. (2009) calculated the distribution of riverine freshwater in southwestern HJB according to $\delta^{18} \mathrm{O}$ measurements in late summer 2005. Their results clearly show concentrations decreasing seaward on scales of $100 \mathrm{~km}$ rather than $10 \mathrm{~km}$. Further evidence is given in Fig 4b, where the simulated surface salinity is shown for the same period as the tracer concentration from Fig. 4a. Striking similarities are visible between the salinity of the water and the tracer concentration, which suggests that river waters are to a large degree responsible for the freshness of the waters offshore during the summer period. This model result is consistent with the observed salinity charts (see section 2, and also the charts from Prinsenberg 1986b) that show similar features during the summer. Finally, Macdonald et al. (1999) report similar observations for the plume of the Mackenzie River in the Beaufort Sea. In the next sections we will investigate the meaning and importance of this offshore transport of the river waters.

\subsection{Exchanges between the Boundary and Interior Regions}

For simplicity we first consider the cross-shore exchanges of freshwater without distinguishing its origin (river or precipitation); we will go back to the specific case of the river waters once the processes involved are identified. We begin by identifying the boundary and interior areas: the boundary holds a narrow, swift flow that follows the shorelines, while the interior has a broad, slow flow following a closed circuit (e.g., Pedlosky, 1996, p. 2). Thus the two regions are naturally identified from the mean streamlines, or more specifically those of the surface currents (first model level, 0-10 m, see Li et al. 2006) since we focus upon the buoyant freshwater. The mean streamlines (Fig. 4c) depict a counter-clockwise flow around Hudson Bay, with the waters leaving Hudson Bay through the easternmost channel, and then heading toward the east along the southern shore of Hudson Strait. The flow is relatively strong in the nearshore region and rather quiescent in the central region. The streamline highlighted in black marks the frontier between the boundary (open streamlines) and interior (closed streamlines) regions. Note that having a streamline as the frontier does not mean the interior is isolated from the boundary: seasonal advection, and eddy exchange of scalars, can act across the mean streamline.

We now examine the contribution of lateral fluxes (i.e. the boundary/interior exchanges) in the freshwater budget of the interior. This budget is shown in Fig. 5a,b, where $V$ stands for the total (solid plus liquid) freshwater content. The volume $V$ undergoes large seasonal variations, decreasing by $225 \mathrm{~km}^{3}$ during the autumn, and increasing during early winter and during summer. It is also seen in Fig. 5b that the large variations in $V$ $(\mathrm{d} V / \mathrm{d} t$, red curve in $\mathrm{b})$ cannot be explained by the divergence of 
ice and by net precipitation, so that lateral exchanges must be responsible for the large variations. In particular, the increase in $V$ during the summer is what is expected from the observed and simulated summer surface salinity charts (see the previous section). The next step is to identify what processes are behind the lateral exchanges.

\subsection{What Regulates the Freshwater Content in the Interior?}

Two processes are likely to contribute to the cross-shore transport of freshwater: 1) Ekman transport in the fresh surface layer (e.g., Lentz, 2004), and 2) eddies formed through baroclinic instability of the boundary current (e.g., Spall, 2004). As a first attempt we will assume the Rossby and horizontal Ekman numbers to be small, so that we neglect exchanges due to eddies and assume that the flow can be decomposed into geostrophic and Ekman components (e.g., Müller, 2006, section 15.2). The latter is defined by the dynamical balance:

$$
f \mathbf{e}_{3} \times \mathbf{u}_{\mathrm{ek}}=\frac{\partial}{\partial z} A_{3} \frac{\partial}{\partial z} \mathbf{u}_{\mathrm{ek}}
$$

where $f$ is the Coriolis parameter, $\mathbf{e}_{3}$ the unit vector pointing upward, $\mathbf{u}_{\mathrm{ek}}$ the Ekman velocity as a function of position and time, $\partial / \partial z$ is the vertical derivative, and $A_{3}$ is the model vertical turbulent viscosity being also a function of position and time. Ekman velocities are computed at each grid point and timestep, with $A_{3} \partial \mathbf{u}_{\mathrm{ek}} / \partial z$ set to the surface stress, and a no-slip condition at the bottom. Note that $\partial \mathbf{u}_{\text {geos }} / \partial z$ is assumed negligible within the Ekman layers. The surface stress is defined as a smooth function of the wind stress (ice-free period) and of the ice-ocean stress (ice-covered period, see Mellor and Kantha 1989). Once the Ekman velocities are obtained, the corresponding freshwater fluxes are calculated using the salinity reference $S_{0}$.

Figure 5c shows the comparison between the lateral exchange of freshwater caused by the true model velocities (red curve) and the lateral exchange of freshwater due to Ekman velocities (green curve). The two timeseries are very close to one another, meaning that Ekman velocities are in a large part responsible for the exchanges of freshwater between the interior and boundary regions. The interior region releases freshwater to the boundary region during the autumn (negative fluxes), and then receives freshwater from the boundary region in early winter and during the summer. These results essentially reflect the variations in the freshwater content of the interior region that were seen previously (Fig. 5b, red curve).

The important role played by the Ekman velocities for the regulation of the freshwater present in the interior means that the stress applied at the surface of the basin exerts a significant control over these exchanges. The dynamical relation between the two is directly obtained by computing the divergence $\boldsymbol{\nabla} \cdot$ of the Ekman volume transport $\mathbf{M}_{\mathrm{s}}=-\mathbf{e}_{3} \times \boldsymbol{\tau}_{\mathrm{s}} /\left(f \rho_{0}\right)($ Ekman, 1905):

$$
\boldsymbol{\nabla} \cdot \mathbf{M}_{\mathrm{s}}=\frac{1}{f \rho_{0}}\left(\boldsymbol{\nabla} \times \boldsymbol{\tau}_{\mathrm{s}}\right)_{3}
$$

where the subscript 3 refers to the vertical component of the curl. Such relation is apparent when comparing the blue curve from Fig. 5d (right hand side of Eq. 6) to the blue and green curves of Fig. 5c (left hand side). The relation can be summarized in the following way. A counter-clockwise tendency in the wind stress (positive curl, $\boldsymbol{\nabla} \times \boldsymbol{\tau}_{\mathrm{s}}>0$ ) forces the surface waters to leave the interior region (divergence, $\boldsymbol{\nabla} \cdot \mathbf{M}_{\mathrm{s}}>0$ ). A clockwise tendency in the wind stress (negative curl, $\boldsymbol{\nabla} \times \boldsymbol{\tau}_{\mathrm{s}}<0$ ) forces the surface waters to enter the interior region (convergence, $\boldsymbol{\nabla} \cdot \mathbf{M}_{\mathrm{s}}<0$ ). These concepts are illustrated in Fig. 6. Note that the horizontal scale of the wind stress field is comparable with the size of the domain.

It is worth noting that Eq. 6 relates the curl of the stress at the surface of the sea to the Ekman volume transport. However it is the Ekman transport of freshwater that is the quantity of interest here, and it could differ appreciably from the volume transport depending on the cross-shore salinity gradients. Figure 5c shows that in fact the volume and freshwater transports share the same seasonal evolution. The salinity field only causes a slight amplification or damping of the seasonality in some periods. In other words, variations in the cross-shore flux of freshwater (a product of velocity and freshwater concentration) are more determined by the velocities than by salinity.

Another dynamical consideration is that the Ekman transport is driven by the stress at the top of the water column, which differs from the wind stress in winter. During this period, the ice cover acts as an intermediary that transfers part of the wind stress to the ocean (sea ice tends to be driven by winds, and damped by its contact with the ocean and by ice-ice interaction; Martinson and Wamser 1990; Steele et al. 1997. This is most likely the case in the interior region since the currents are so weak, see Fig. 4c, and Markham 1986). It raises the question of whether sea ice plays a role in the seasonality of the Ekman exchange. Figure 5d shows that the curl of the surface stress and wind stress are identical during the ice-free period (as expected), and similar during the ice-thick period (Jan.-June). Therefore the sea ice in the interior of Hudson Bay is mostly , mobile (in agreement with Markham 1986) and allows, to a large extent, the transmission of the wind stress to the water column. We conclude that the sea ice plays a small role in the seasonality of the exchange between the interior and boundary regions.

The last two sections presented the seasonal variability of the freshwaters and the main process driving the cross-shore fluxes of freshwater. We will now examine how these findings apply to the specific case of the river freshwater.

\subsection{The Pathway and Transit Time of the River Waters}

The pathway and transit time of the river waters is examined by once again making use of the numerical river water tracer described in section Method. In this experiment, the injection of the tracer starts on 1 April (beginning of the freshet) and lasts for one year (i.e. until the beginning of the next freshet). Note that the river forcing remains active at all time even though the injection of river tracer stops after one year. Also, although this tracer experiment spans over 10 years, it is the same seasonal wind and river forcing that is applied each year (see Method).

Once the injection period is completed, the volume of river tracer, $R(t)$, is gradually exported out of HJB by the circulation, 
and $R(t)$ can be represented as either a linearly or exponentially decreasing function:

$$
R(t \geq 0)= \begin{cases}R_{0}\left(1-\frac{t}{2 T_{1}}\right) & \text { (linear) } \\ R_{0} \exp \left(-\frac{t}{T_{2}}\right) & \text { (exponential) }\end{cases}
$$

where $R_{0}$ is the volume of river tracer present in HJB at the end of the injection period (at $t=0$ ), and $T_{1}, T_{2}$ are constants obtained from regression of the model results. The time interval between the injection of a tracer parcel and the moment it leaves HJB is defined as its transit time (Zimmerman, 1988). Some of the dyed waters leave the system faster than others and so the values reported below correspond to the average transit time for the whole volume of tracer injected. Following Zimmerman (1988), and assuming for simplicity that all river tracer parcels entered HJB at $t=0$, the average transit time is given by:

$$
T=-\int_{0}^{\infty} t \frac{1}{R_{0}} \frac{\mathrm{d} R}{\mathrm{~d} t} \mathrm{~d} t
$$

By inserting Eq. 7 into Eq. 8, we see that $T_{1}, T_{2}$ correspond to the average transit time in the linear and exponential cases, respectively.

The red curve of Fig. 7a shows the volume of dyed river water within the basin during the injection period and after, normalized by the annual river input. The volume of dyed river water increases rapidly during the injection period (ending at time 0 ) and gradually decreases afterward. About $15 \%$ of the river waters have left the basin when the injection period comes to an end (i.e. at time 0). The green and blue curves also represent the amount of dyed river water, but within the boundary and interior regions instead of the whole bay. Initially there is no river waters within the interior region since the river inflow occurs in the boundary region. The volume of river water within the interior (blue curve) increases during the summer of each year, while release occurs during the autumn (see the close-up in Fig. 7b). This is consistent with the seasonal exchange of freshwater identified in the previous sections (Fig. 5c), and it shows that freshwater of riverine origin effectively contributes to the seasonal exchange of freshwater. Fig. $7 \mathrm{~b}$ also shows that most interior/boundary exchanges occur during the ice-free period, and thus what is exchanged is mostly liquid river tracer. Finally, Fig. 7a shows that $\sim 20 \%$ of the river runoff is transformed into ice, a proportion similar to what is observed in front of the Mackenzie River in the Arctic Ocean (15\%, Macdonald et al., 1995).

The volume of river water within the interior increases up to the summer of year 1 (reaching one quarter of the annual river input), and decreases afterward (Fig. 7b). At this point the interior region has become a net source of river water for the boundary region (the exchanges between the interior and boundary are illustrated in Fig. 8). From Fig. 7a, this flux from the interior to the boundary region increases until time 3.5, when the slope of the blue and green curves become equal, meaning that the bay is now releasing equal amounts from the interior and boundary regions. The influence of the interior region on the rate of flushing of the whole bay is illustrated by the dotted and dashed lines in Fig. 7a. Prior to year 3, the bay linearly releases river water that mostly comes from the boundary (dotted line). But from year 3 and onward, the influence of the interior becomes significant (blue and green curves share the same slope) and the rate of release slows down (dashed line). This means that the excursion in the interior contributes to lengthen the transit time of the river tracer. This is quantified by comparing the dotted and dashed lines. The dotted line (years 0-3; little influence from interior) represents a transit time of $T_{1}=2.2$ years, while the dashed line gives a longer transit time of $T_{2}=3.0$ years.

\section{Discussion}

The objective of this study was to examine the pathway, or kinematics, of the river waters of HJB. The study necessitated a certain number of simplifications, one of them being that we examined in detail the components of the freshwater balance over a finite period of time (August 2003-August 2004). It raises the question of whether these components and processes have the same importance during other years. We speculate that it is the case, given the large seasonality of the insolation at these high latitudes that leads to particularly marked seasonal cycles and, in comparison, small interannual variability. For instance, the seasonality of the bay's waters and that of its hydrologic forcing in 2003-2004 are qualitatively the same, and quantitatively close, to those from the 1996-1998 period considered by Saucier et al. (2004a). We also examined the generality of our analysis regarding the curl of the wind stress by comparing them with NCEP winds (National Centers for Environmental Prediction, Kalnay et al., 1996) covering a 30-year period (1979-2008). The curl over the 30 years has a mean value similar to that from the 2003-2004 forcing, and seasonal periods of strongly cyclonic/lightly anticyclonic conditions similar to those described in section 3.4 (see also Sutherland et al., this issue, on the role of the curl during other years). For these reasons, we believe the results obtained here with the forcing from 2003-2004 are likely to be generally applicable.

Another methodological consideration is that mesoscale eddies are partly resolved by the $10 \mathrm{~km}$ model grid (eddy-permitting resolution). Such eddies are known to contribute significantly to the along-shore transport of freshwater in Hudson Strait (Sutherland et al., this issue). Could cross-shore eddy transport play a major role in eddy-resolving simulations of HJB? Although increased eddy activity is expected at finer resolution, it seems unlikely to become the dominant process (i.e. overcoming the Ekman transport) simply by changing the resolution from 10 to $3 \mathrm{~km}$ (eddy resolving). Comparison with observations (Fig. 2) show that the current resolution is sufficient to yield realistic results at the scales of interest. We also note that the Ekman dynamics highlighted in this study (e.g., Eq. 6) do not depend on the horizontal resolution of the ocean model; this dynamics mostly depend on the wind forcing, which originates from a highly realistic regional atmospheric model (see Method). Finally, eddy fluxes are unlikely to dominate the cross-shore exchanges since the positive $P-E$ rate over the interior region requires a net lateral flux of freshwater directed onshore (i.e. divergent, like the mean Ekman fluxes), while eddy diffusion of freshwater must be directed offshore (downgradient; see the 
salinity charts in Fig. 2). These considerations support the results from the simulations.

We initially envisioned two scenarios for the fate of the river waters of HJB. In scenario 1 , the outflow is a function of the river runoff, the distance to the mouth of the bay, and the advective velocity. This corresponds to the study from Déry et al. (2005), who illustrated how the spatially-distributed runoff in the wide bay leads to an outflow over the Labrador Shelf made of river waters from the three preceding years. This basic conclusion is recovered here with a transit time of 3.0 years. On the other hand, our results show that a significant fraction (one quarter) of the annual river input is diverted to the interior of the basin because of the winds, as in scenario 2. It is estimated that this detour amounts to 0.8 years within the overall transit time of 3.0 years. Therefore, HJB would stand between scenarios 1 and 2. It is interesting that scenario 2 was also encountered by Proshutinsky et al. (2009) who examined the basin-scale mechanisms regulating anomalies in the freshwater content of the Beaufort Sea/Gyre. These authors find that the seasonality of the freshwater content is controlled by variations in the curl of the wind stress (consistent with the numerical results of Omstedt et al., 1994), which is similar to what is found in our study.

The results from the study also offer an explanation for the relatively fresh waters of HJB (compare its surface salinity, or salinity averaged between $0-150 \mathrm{~m}$, with the other Arctic seas, e.g., Steele et al., 2001). First, the transit time calculated (3.0 years on average) means that the runoff from different years get superimposed within the basin. Then, this freshwater is spatially redistributed by the winds instead of being confined to the nearshore region. This offshore excursion of river water could play a significant role in the redistribution of river tracers such as mercury and colored dissolved organic matter (CDOM). Through the seasonal excursion in the interior, these substances can impact the marine life outside of the nearshore region. The offshore excursion is also likely to contribute to the stratification and oligotrophic conditions observed in the interior region (Kuzyk et al., 2010) where vertical mixing can be critical. This is in contrast with the boundary region, where nutrients can be made available through the buoyancy-driven circulation that upwells deep waters (Kuzyk et al., 2010).

Although the study specifically examined the cross-shore transport of river waters within HJB, other processes act to spatially distribute the river waters. One of them is the winter convection that is particularly intense in the large polynya of northwestern HJB (Markham, 1986; Prinsenberg, 1987; Saucier et al., 2004a). Granskog and al. (this issue) estimate, from $\delta^{18} \mathrm{O}$ measurements, that $6-18 \%$ of the annual river input is exported in the deep layer by winter densification in polynyas. This interesting result supports the idea that the pathway of the river waters within $\mathrm{HJB}$ is not trivial.

\section{Conclusions}

The kinematics of the river waters of Hudson and James bays were examined using a realistic regional sea ice-ocean coupled model whose results compare favorably with observations. The simulations show that winds produce (through Ek- man dynamics) a seasonal advection of the river waters in the cross-shore direction. We estimate that this cross-shore transport involves about $25 \%$ of the annual river input. Such crossshore transport of river water modifies the density field offshore, and could play a significant role in the dispersion of river tracers such as mercury and colored dissolved organic matter, with potential implications for marine life.

\section{Acknowledgements}

This work is a contribution to the Freshwater-Marine Coupling project of the ArcticNet network of Canada. We thank NSERC and the Canada Research Chairs program for funding. FS acknowledges support from NSF OCE-0751554 and ONR N00014-08-10490. This work has greatly benefited from suggestions by the editors of this special issue and the reviewers. We want to thank the Department of Fisheries and Oceans of Canada, their technicians, the captains and crews of the CCGS Radisson, DesGroseillers, Martha Black, and Amundsen. We also thank S. Senneville for technical support. NCEP Reanalysis data provided by the NOAA/OAR/ESRL PSD, Boulder, Colorado, USA, from their Web site at http://www.esrl.noaa.gov/psd/.

Backhaus, J. O., 1983. A semi-implicit scheme for the shallow water equations for application to shelf sea modelling. Cont. Shelf Res. 2 (4), 243-254.

Backhaus, J. O., 1985. A three-dimensional model for the simulation of shelf sea dynamics. Dtsch. Hydrogr. Z. 38 (4), 165-187.

Barber, F. G., 1965. Current observations in Fury and Hecla Strait. J. Fish. Res. Bd. Can. 22, 225-229.

Canuto, V. M., Howard, A., Cheng, Y., Dubovikov, M. S., 2001. Ocean turbulence. Part 1: One-point closure model-Momentum and heat vertical diffusivities. J. Phys. Ocean. 31, 1413-1426.

Côté, J., Gravel, S., Méthot, A., Patoine, A., Roch, M., Staniforth, A., 1998. The operational CMC/MRB Global Environmental Multiscale (GEM) model: Part I-Design considerations and formulation. Mon. Weather Rev. 126, 1373-1395.

Déry, S. J., Mlynowski, T. J., Hernández-Henríquez, J. M., Straneo, F., 2010. Interannual variability and interdecadal trends in Hudson Bay streamflow. J. Mar. Syst. xxx, xxx, this issue.

Déry, S. J., Stieglitz, M., McKenna, E. C., Wood, E. F., 2005. Characteristics and trends of river discharge into Hudson, James, and Ungava Bays, 19642000. J. Clim. 18, 2540-2557.

Ekman, V. W., 1905. On the influence of the Earth's rotation on ocean-currents. Arkiv för Matematik, Astronomi och Fysik 2 (11), 1-53.

Gill, A., 1982. Atmosphere-ocean dynamics. Academic Press, London (UK).

Granskog, M. A., al., 2010. Freshwater composition and distribution in Hudson Bay using oxygen isotopes. J. Mar. Syst. xxx, xxx, this issue.

Granskog, M. A., Macdonald, R. W., Kuzyk, Z. A., Senneville, S., Mundy, C. J., Barber, D. G., Stern, G. A., Saucier, F. J., 2009. Coastal conduit in southwestern Hudson Bay (Canada) in summer: Rapid transit of freshwater and significant loss of colored dissolved organic matter. J. Geophys. Res. 114 (C08012), doi:10.1029/2009JC005270.

Granskog, M. A., Macdonald, R. W., Mundy, C. J., Barber, D. G., 2007. Distribution, characteristics and potential impacts of chromophoric dissolved organic matter (CDOM) in Hudson Strait and Hudson Bay, Canada. Cont. Shelf Res. 27, 2032-2050, doi:10.1016/j.csr.2007.05.001.

Hare, A., Stern, G. A., Macdonald, R. W., Kuzyk, Z., Wang, F., 2008. Contemporary and preindustrial mass budgets of mercury in the Hudson Bay Marine System: The role of sediment recycling. Sci. Total Environ. 406, 190-204.

Hibler, III, W. D., 1979. A dynamic thermodynamic sea ice model. J. Phys. Oceanogr. 9, 815-846.

Hochheim, K., Lukovich, J., Barber, D., 2010. Atmospheric forcing of sea ice in Hudson Bay during spring, 1980-2007. J. Mar. Syst. xxx, xxx, this issue.

Hunke, E. C., Dukowicz, J. K., 1997. An elastic-viscous-plastic model for sea ice dynamics. J. Phys. Oceanogr. 27 (9), 1849-1867. 
Jahn, A., Tremblay, L. B., Newton, R., Holland, M. M., Mysak, L. A., Dmitrenko, I. A., 2010. A tracer study of the Arctic Ocean's liquid freshwater export variability. J. Geophys. Res. 115 (C07015), doi:10.1029/2009JC005873.

Kalnay, E., Kanamitsu, M., Kistler, R., Collins, W., Deaven, D., Gandin, L., Iredell, M., Saha, S., White, G., Woollen, J., Zhu, Y., Leetmaa, A., Reynolds, R., Chelliah, M., Ebisuzaki, W., Higgins, W., Janowiak, J., Mo, K., Ropelewski, C., Wang, J., Jenne, R., Joseph, D., 1996. The NCEP/NCAR 40year reanalysis project. Bull. Amer. Meteor. Soc. 77, 437-470.

Kuzyk, Z. A., Macdonald, R. W., Tremblay, J., Stern, G. A., 2010. Elemental and stable isotopic constraints on river influence and patterns of nitrogen cycling and biological productivity in Hudson Bay. Cont. Shelf Res. 30, 163-176, doi:10.1016/j.csr.2009.10.014.

Lammers, R. B., Shiklomanov, A. I., Vörösmarty, C. J., Fekete, B. M., Peterson, B. J., 2001. Assessment of contemporary Arctic river runoff based on observational discharge records. J. Geophys. Res. 106 (D4), 3321-3334.

Lapoussière, A., Michel, C., Gosselin, M., Poulin, M., 2009. Spatial variability in organic material sinking export in the Hudson Bay system, Canada, during fall. Cont. Shelf Res. 29, 1276-1288.

Lentz, S. J., 2004. The response of buoyant coastal plumes to upwellingfavorable winds. J. Phys. Oceanogr. 34, 2458-2469.

Li, Z., Chao, Y., McWilliams, J. C., 2006. Computation of the streamfunction and velocity potential for limited and irregular domains. Mon. Wea. Rev. 134, 3384-3394.

Macdonald, R. W., Carmack, E. C., McLaughlin, F. A., Falkner, K. K., Swift, J. H., 1999. Connections among ice, runoff and atmospheric forcing in the Beaufort Gyre. Geophys. Res. Lett. 26 (15), 2223-2226.

Macdonald, R. W., Paten, D. W., Carmack, E. C., Omstedt, A., 1995. The freshwater budget and under-ice spreading of Mackenzie River water in the Canadian Beaufort Sea based on salinity and ${ }^{18} \mathrm{O} /{ }^{16} \mathrm{O}$ measurements in water and ice. J. Geophys. Res. 100 (C1), 895-919.

Markham, W., 1986. The ice cover. In: Martini, I. (Ed.), Canadian Inland Seas. Elsevier oceanogr. series, pp. 101-116.

Martin, P. J., 1985. Simulation of the mixed layer at OWS November and Papa with several models. J. Geophys. Res. 90 (C1), 903-916.

Martinson, D. G., Wamser, C., 1990. Ice drift and momentum exchange in winter Antarctic pack ice. J. Geophys. Res. 95 (C2), 1741-1755.

Matsumoto, K., Takanezawa, T., Ooe, M., 2000. Ocean tide models developed by assimilating Topex/Poseidon altimeter data into a hydrodynamical model: A global model and a regional model around Japan. J. Oceanogr. 56, 567-581.

McPhee, M. G., Proshutinsky, A., Morison, J. H., Steele, M., Alkire, M. B., 2009. Rapid change in the freshwater content of the Arctic Ocean. Geophys. Res. Lett. 36 (L10602), doi:10.1029/2009GL037525.

Mellor, G. L., Kantha, L., 1989. An ice-ocean coupled model. J. Geophys. Res. 94 (C8), 10937-10954.

Mellor, G. L., Yamada, T., 1982. Development of a turbulence closure model for geophysical fluid problems. Rev. Geophys. Space Phys. 20 (4), 851-875.

Müller, P., 2006. The Equations of Oceanic Motions, 1st Edition. Cambridge University Press.

Myers, R. A., Akenhead, S. A., Drinkwater, K., 1990. The influence of Hudson Bay runoff and ice-melt on the salinity of the inner Newfoundland Shelf. Atmos.-Ocean 28, 241-256.

Omstedt, A., Carmack, E. C., Macdonald, R. W., 1994. Modeling the seasonal cycle of salinity in the Mackenzie shelf/estuary. J. Geophys. Res. 99 (C5), 10011-10021.

Pedlosky, J., 1996. Ocean Circulation Theory, 1st Edition. Springer-Verlag.

Prinsenberg, S. J., 1980. Man-made changes in the freshwater input rates of Hudson and James bays. Can. J. Fish. Aquat. Sci. 37 (7), 1101-1110.

Prinsenberg, S. J., 1984. Freshwater contents and heat budgets of James Bay and Hudson Bay. Cont. Shelf Res. 3 (2), 191-200.

Prinsenberg, S. J., 1986a. The circulation pattern and current structure of Hudson Bay. In: Martini, I. (Ed.), Canadian Inland Seas. Elsevier oceanogr. series, pp. 187-203.

Prinsenberg, S. J., 1986b. Salinity and temperature distributions of Hudson Bay and James Bay. In: Martini, I. (Ed.), Canadian Inland Seas. Elsevier oceanogr. series, pp. 163-186.

Prinsenberg, S. J., 1987. Seasonal current variations observed in western hudson bay. J. Geophys. Res 92 (C10), 10756-10766.

Prinsenberg, S. J., 1988. Ice-cover and ice-ridge contributions to the freshwater contents of Hudson Bay and Foxe Basin. Arctic 41 (1), 6-11.
Proshutinsky, A., Krishfield, R., Timmermans, M.-L., Toole, J., Carmack, E., McLaughlin, F., Williams, W. J., Zimmermann, S., Itoh, M., Shimada, K., 2009. Beaufort Gyre freshwater reservoir: State and variability from observations. J. Geophys. Res. 114 (C00A10), doi:10.1029/2008JC005104.

Sadler, H. E., 1982. Water flow into Foxe Basin through Fury and Hecla Strait. Nat. Can. 109, 701-707.

Saucier, F. J., Senneville, S., Prinsenberg, S. J., Roy, F., Smith, G., Gachon, P., Caya, D., Laprise, R., 2004a. Modelling the sea ice-ocean seasonal cycle in Hudson Bay, Foxe Basin and Hudson Strait, Canada. Clim. Dyn. 23 (3-4), 303-326, doi:10.1007/s00382-004-0445-6.

Saucier, F. J., Starr, M., Harvey, M., Therriault, J. C., 2004b. Expédition MERICA 2003: Suivi et étude du climat et de la productivité de la baie d'Hudson. Nat. Can. 128, 108-110.

Semtner, A. J., 1976. A model for the thermodynamic growth of sea ice in numerical investigations of climate. J. Phys. Oceanogr. 6, 379-389.

Sibert, V., Zakardjian, B., Le Clainche, Y., Gosselin, M., Starr, M., Senneville, S., 2010. Spatial and temporal variability of primary production over the Hudson Bay, Foxe Basin and Hudson Strait marine system via coupled biophysical models. J. Mar. Syst. Xxx, Xxx, this issue.

Spall, M. A., 2004. Boundary currents and watermass transformation in marginal seas. J. Phys. Oceanogr. 34, 1197-1213.

Steele, M., Morley, R., Ermold, W., 2001. PHC: A global ocean hydrography with a high quality Arctic Ocean. J. Clim. 14, 2079-2087.

Steele, M., Zhang, J., Rothrock, D., Stern, H., 1997. The force balance of sea ice in a numerical model of the Arctic Ocean. J. Geophys. Res. 102 (C9), 21061-21079.

Straneo, F., Saucier, F. J., 2008a. The Arctic-subarctic exchange through Hudson Strait. In: Dickson, R., Meincke, J., Rhines, P. (Eds.), Arctic-Subarctic ocean fluxes. Springer Science, Ch. 10, pp. 249-261.

Straneo, F., Saucier, F. J., 2008b. The outflow from Hudson Strait and its contribution to the Labrador Current. Deep Sea-Res. I 55 (8), 926-946, doi:10.1016/j.dsr.2008.03.012.

Sutherland, D., Straneo, F., Lentz, S. J., St-Laurent, P., 2010. Observations of fresh, anticyclonic eddies in the Hudson Strait outflow. J. Mar. Syst. xxx, $\mathrm{xxx}$, this issue.

Zedler, S. E., Niiler, P. P., Stammer, D., Terrill, E., Morzel, J., 2009. Ocean's response to Hurricane Frances and its implications for drag coefficient parameterization at high wind speeds. J. Geophys. Res. 114 (C04016), doi:10.1029/2008JC005205.

Zimmerman, J. T. F., 1988. Estuarine residence times. In: Kjerfve, B. (Ed.), Hydrodynamics of estuaries. Vol. 1. CRC Press, pp. 75-84. 
Table 1: Annual budget (August 2003 to August 2004) for the freshwater (FW) and volume (Vol.) of Hudson and James bays, in km ${ }^{3} \mathrm{y}^{-1}$ relative to $S_{0}=33$ psu.

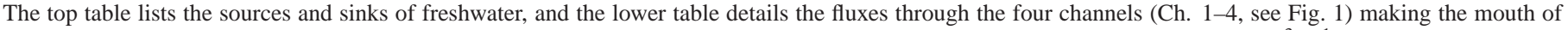

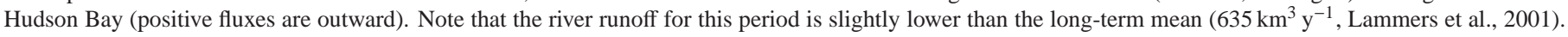
$P-E$ stands for precipitation minus evaporation rate.

\begin{tabular}{ccccccccccccc}
\hline & Riv. + & $P-E$ & - & Growth & + & Melt & $=$ & Net Flux & + & Residual \\
$607+$ & 222 & - & 729 & + & 649 & $=$ & 743 & + & 6 \\
\hline & Net Flux & $=$ & Ch. 1 & + & Ch. 2 & + & Ch. 3 & + & Ch. 4 & + & Residual \\
FW & 743 & $=$ & -16 & + & -57 & + & 14 & + & 802 & + & - \\
Vol. & 607 & $=$ & -556 & + & -2026 & + & -3474 & + & 6615 & + & 48 \\
\hline
\end{tabular}
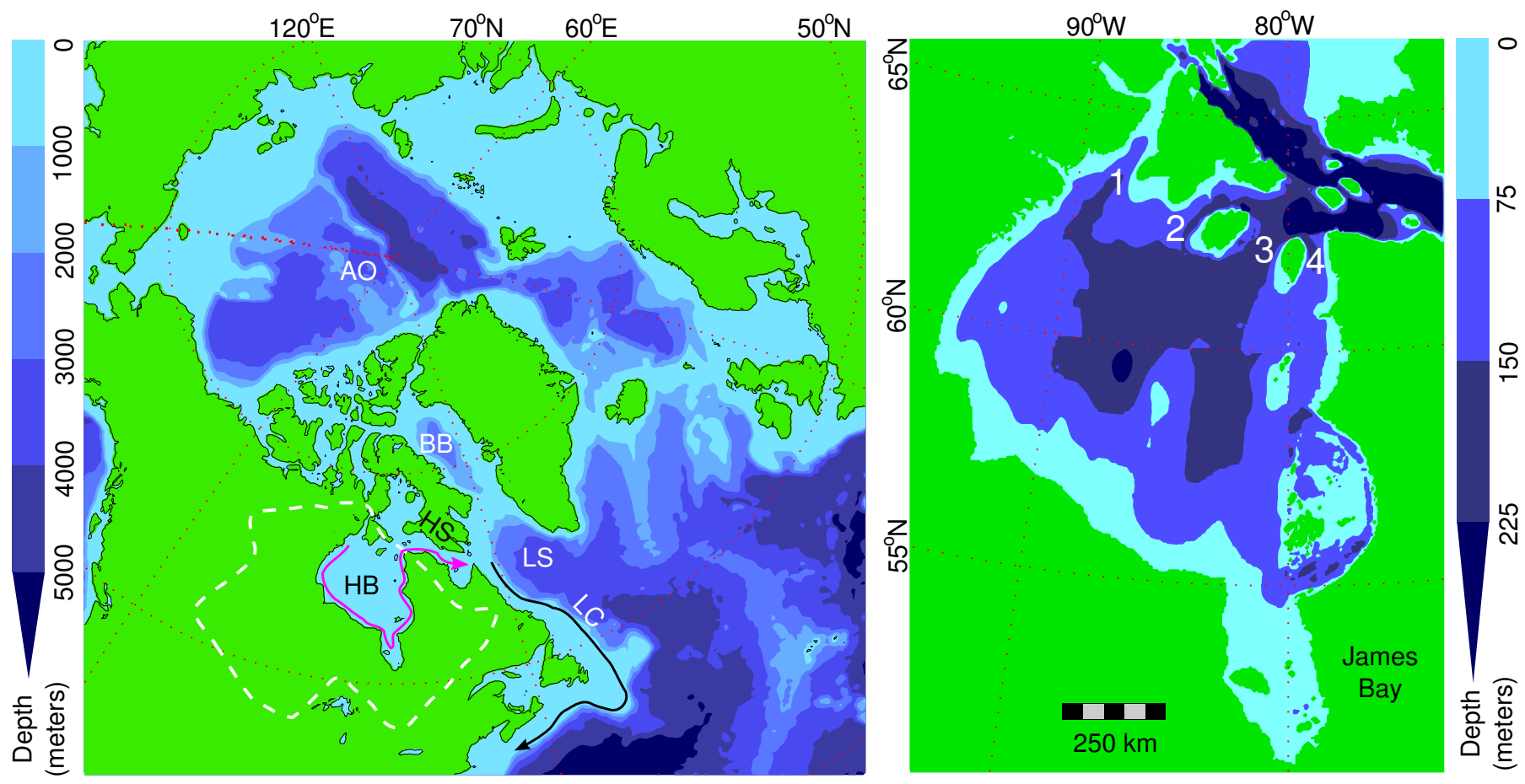

Figure 1: (left) Hudson Bay (HB) within the Arctic region. The drainage basin of HJB is shown by the white dashed line. Also shown are the basins surrounding HB: Hudson Strait (HS), Labrador Sea (LS), Baffin Bay (BB), and Arctic Ocean (AO). The surface currents of HB and the Labrador Current (LC) are schematized by the magenta and black arrows respectively. (right) Bathymetry of Hudson and James bays, with the four channels of Hudson Bay being labeled 1-4. 

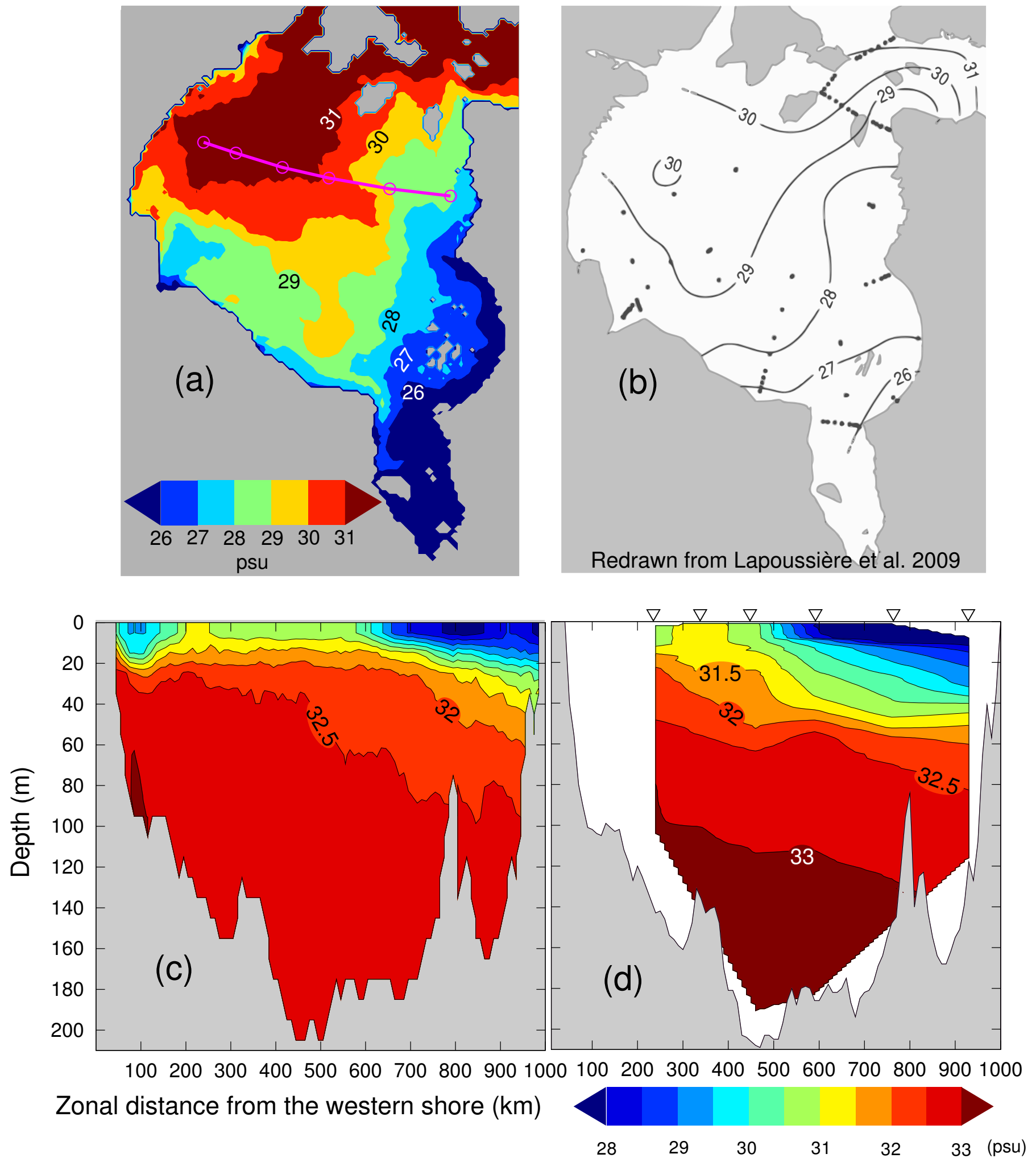

Figure 2: (top) Surface salinity in September according to a) the simulation (year 2003), and b) observations (year 2005, from Lapoussière et al. 2009). The magenta line in a) gives the location of the transect in c) and d). (bottom) Salinity along $61^{\circ} \mathrm{N}$ in August 2003 according to c) the simulation, and d) observations from six stations $(\nabla$ symbol $)$. 


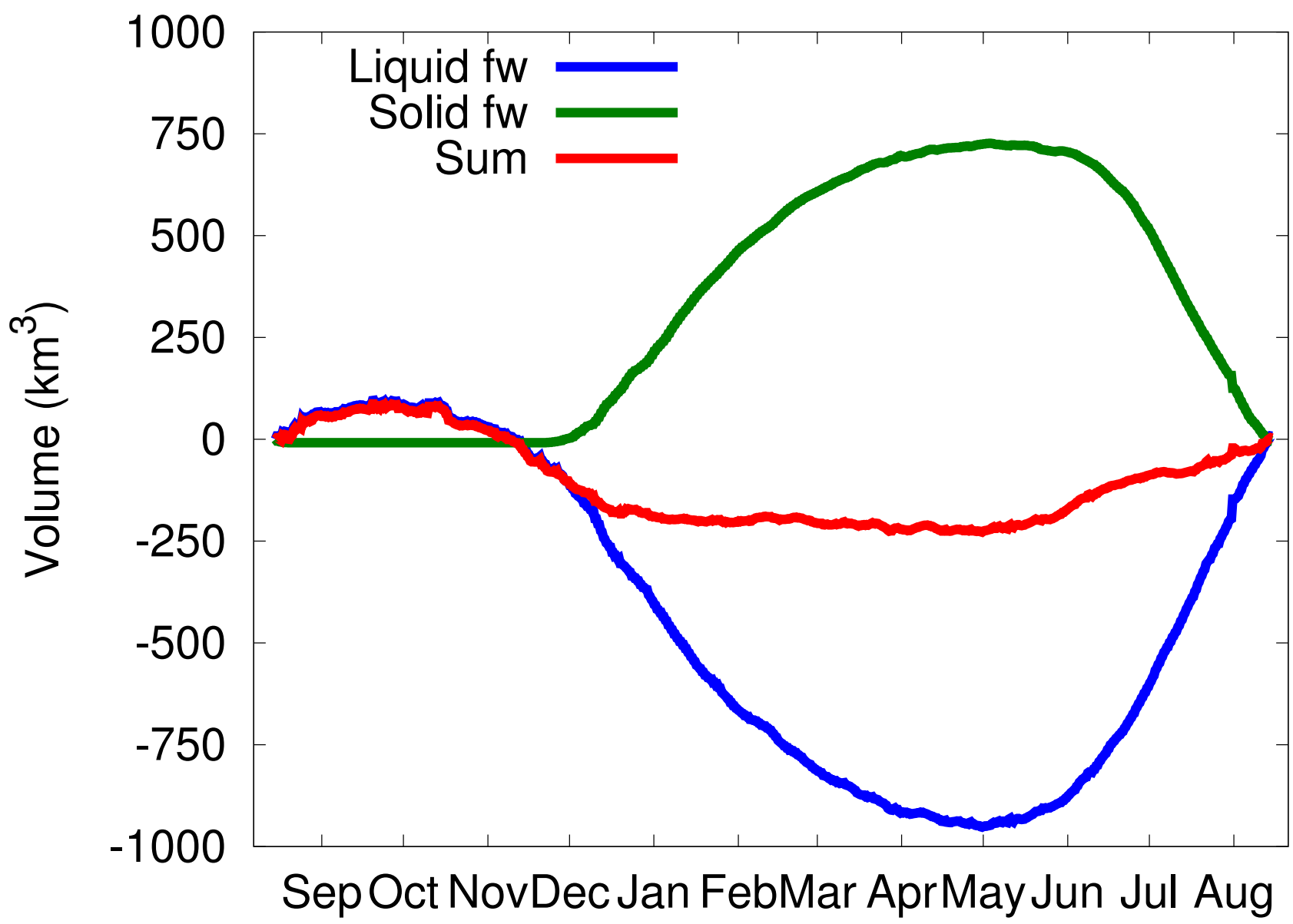

Figure 3: Volume of freshwater (fw) in HJB over the year, referenced to its initial value. 


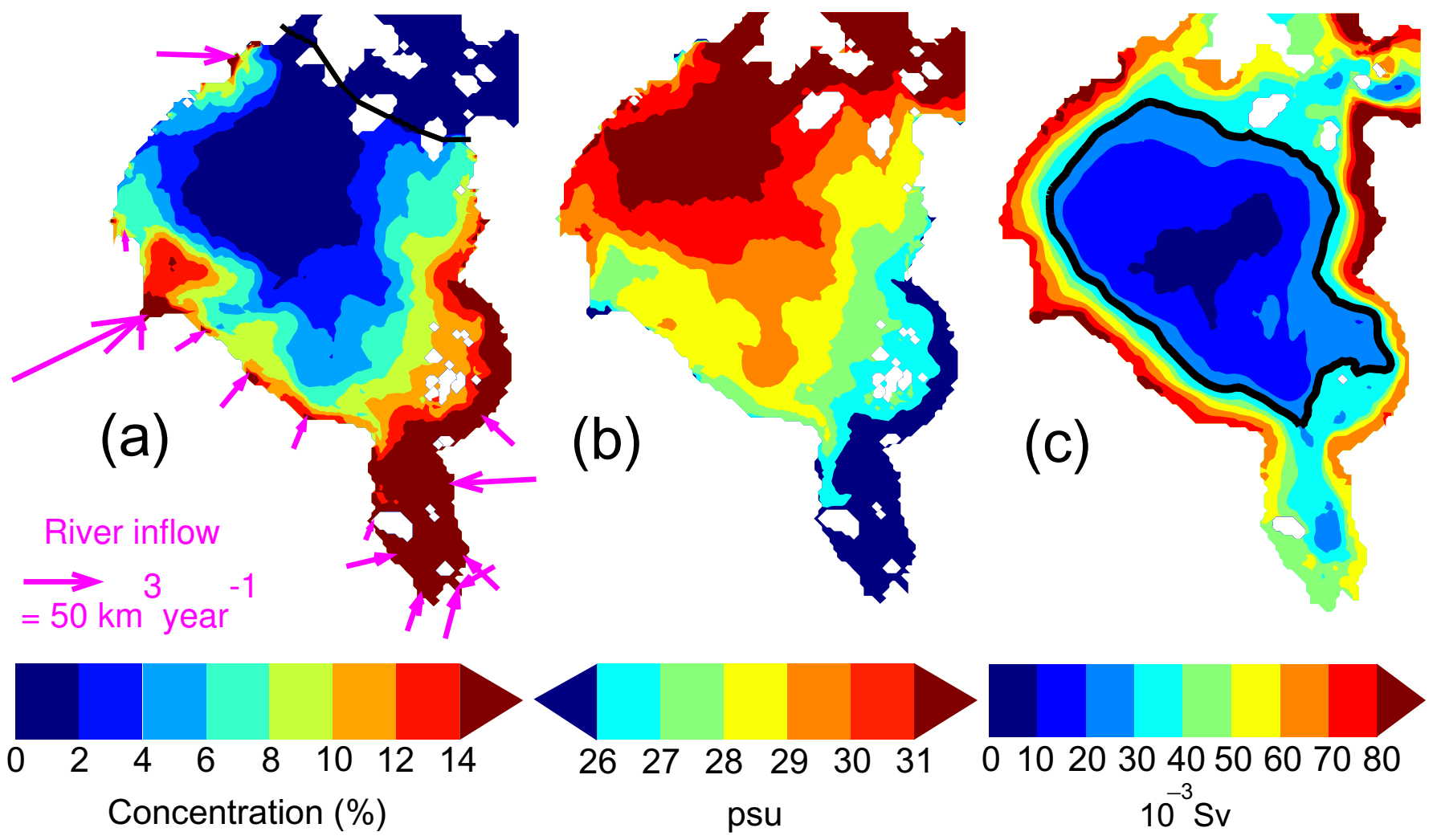

Figure 4: a) Spatial distribution of the river tracer during the summer. The black lines delimitate the extent of the tracer experiment. The arrows show the location and mean discharge of the rivers in HJB. b) Simulated sea surface salinity for the same period. c) Streamfunction for the mean surface currents of the basin. 

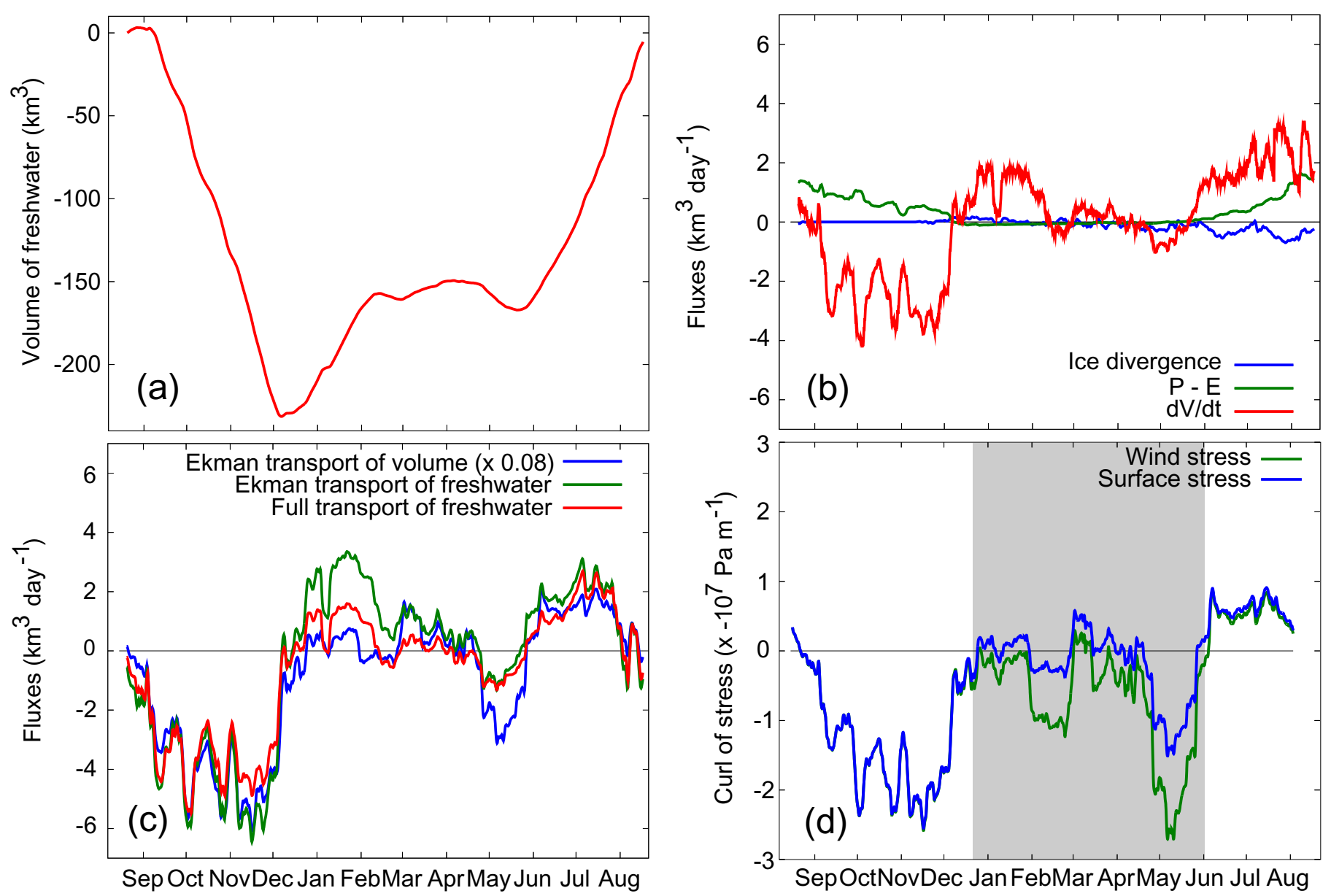

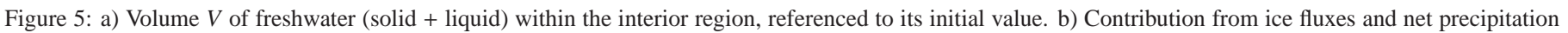

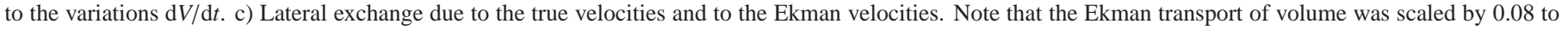

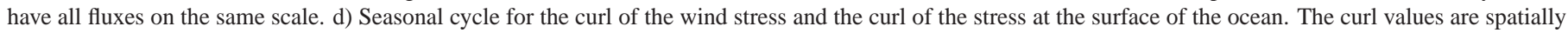
averaged over the interior of HJB. The period when the ice cover is above $85 \%$ is highlighted. 

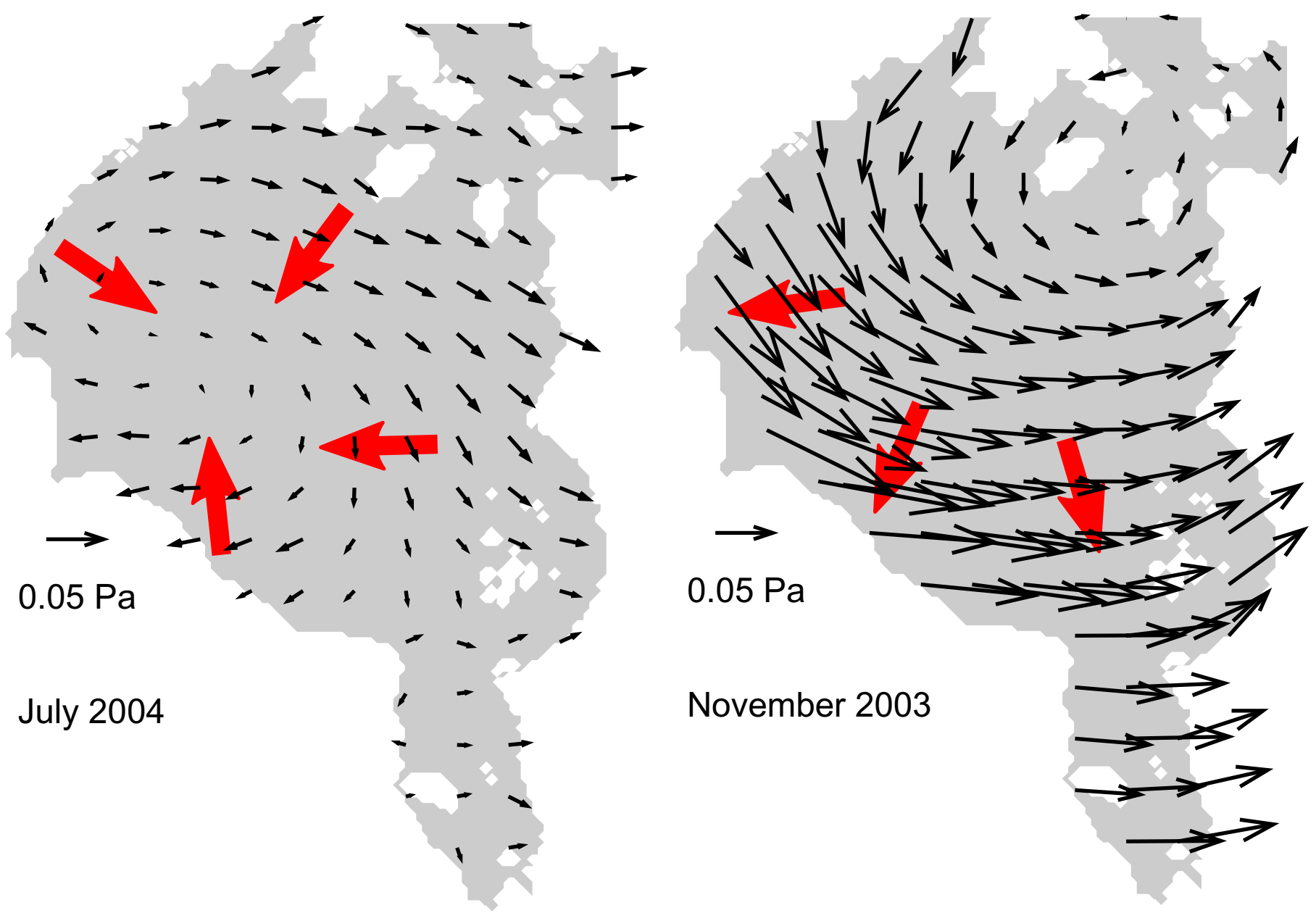

Figure 6: Mean stress (black arrows) at the ocean surface for two contrasting periods. Ekman transport (red arrows) is directed toward the right of the stress. The wind stress is taken from the model forcing (see Method). 

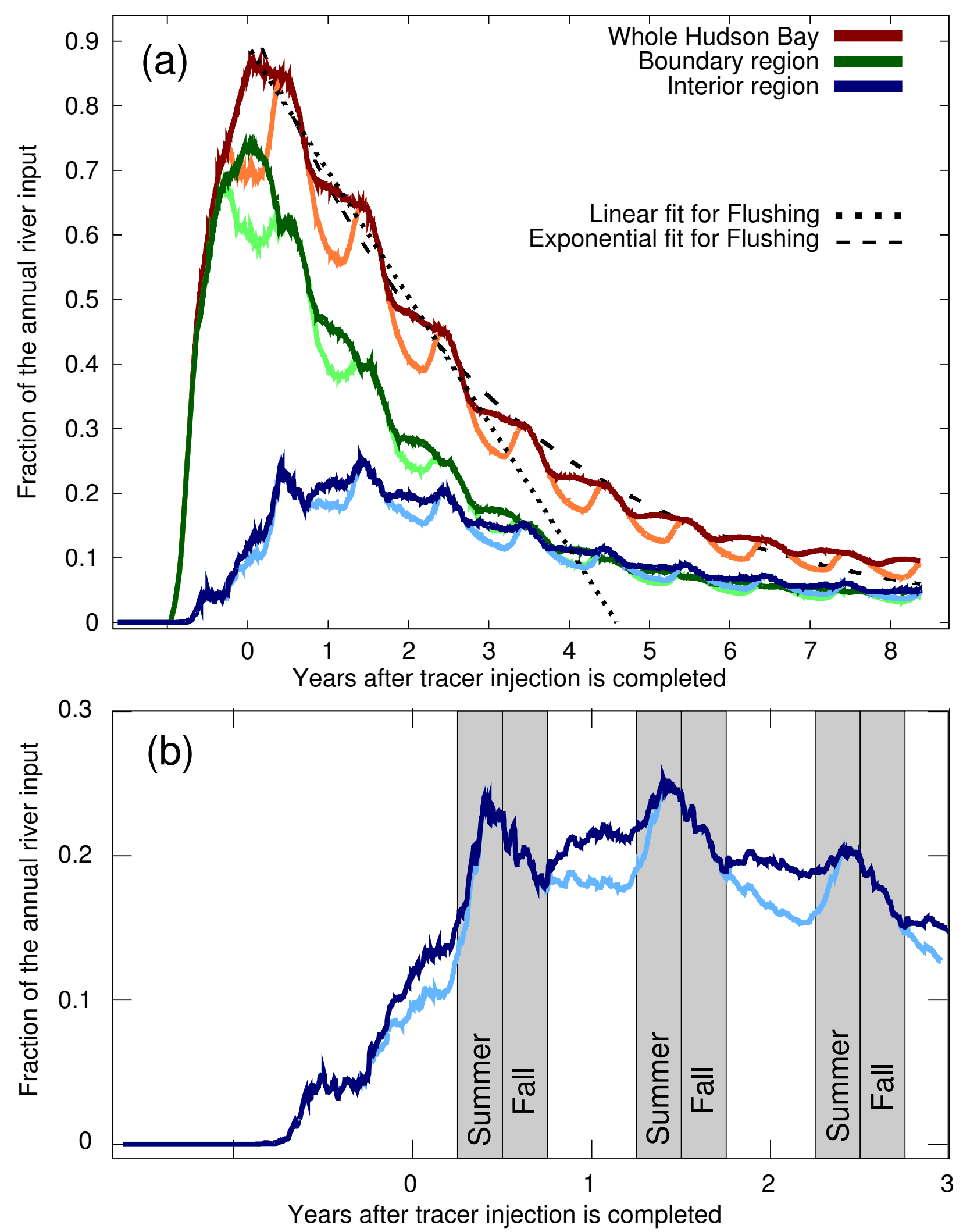

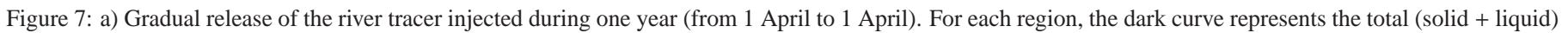

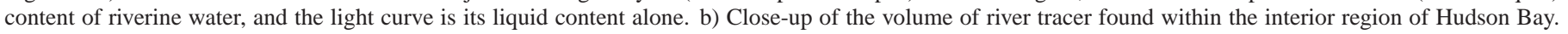
The volume increases (decreases) during the summer (fall). 


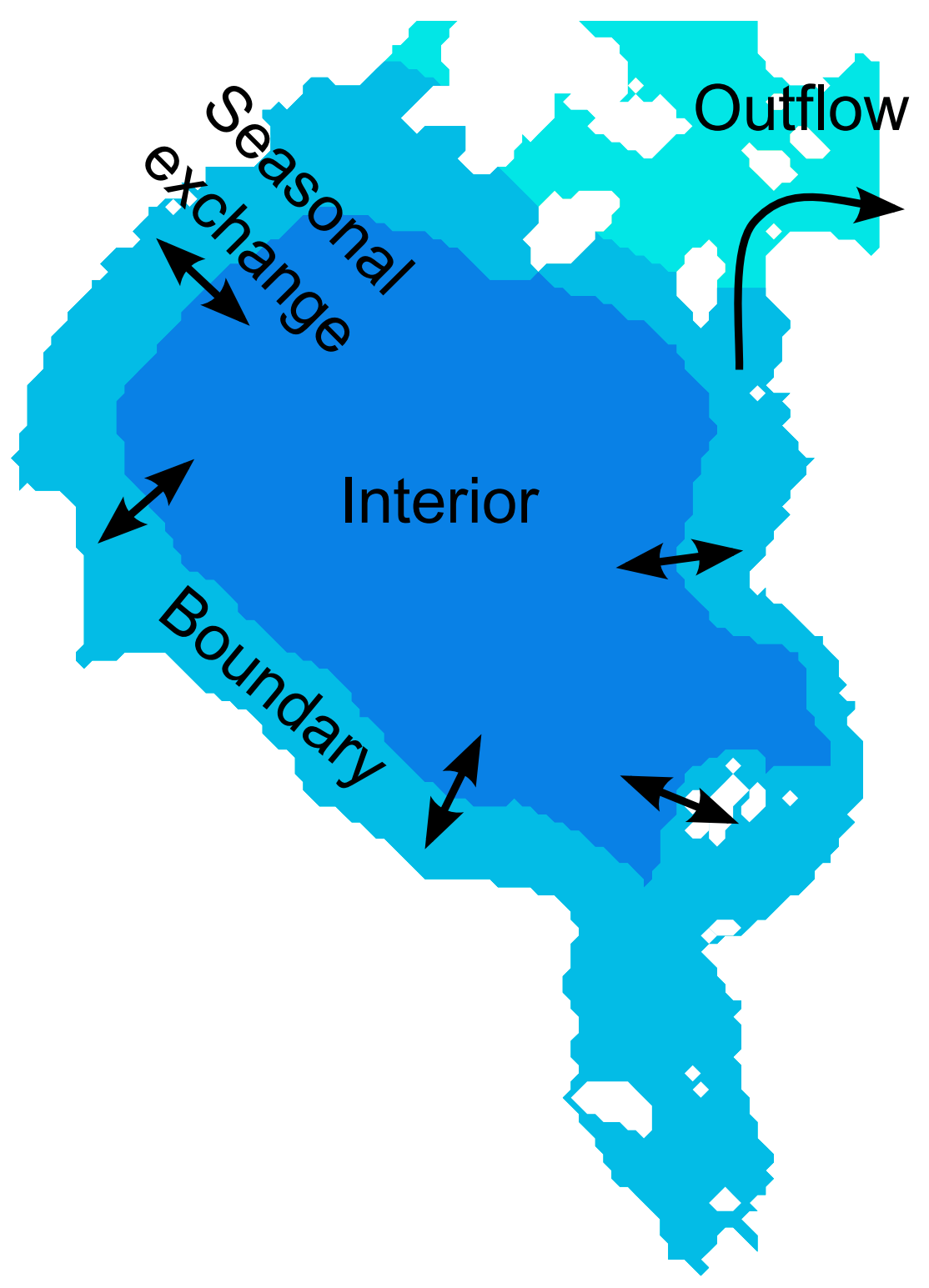

Figure 8: Schematic for the fluxes of river tracer once the injection is completed. Note that the interior region cannot export the river tracer directly outside of Hudson Bay; it can only exchange river tracer with the boundary region. 